\title{
Contributions of gas flaring to a global air pollution hotspot: spatial and temporal variations, impacts and alleviation
}

\author{
*Obinna C.D. Anejionu ${ }^{1}$, J. Duncan Whyatt ${ }^{1}$, G. Alan Blackburn ${ }^{1}$ and Catheryn S. \\ Price $^{2}$ \\ ${ }^{1}$ Lancaster Environment Centre, Gordon Manley Building, \\ Lancaster University, Lancaster. United Kingdom, LA1 4YQ \\ ${ }^{2}$ Cambridge Environmental Research Consultants (CERC) \\ Cambridge, United Kingdom, CB2 1SJ
}

\section{Abstract}

Studies of environmental impacts of gas flaring in the Niger Delta are hindered by limited access to official flaring emissions records and a paucity of reliable ambient monitoring data. This study uses a combination of geospatial technologies and dispersion modelling techniques to evaluate air pollution impacts of gas flaring on human health and natural ecosystems in the region. Results indicate that gas flaring is a major contributor to air pollution across the region, with concentrations exceeding WHO limits in some locations over certain time periods. Due to the predominant south-westerly wind, concentrations are higher in some states with little flaring activity than in others with significant flaring activity. Twenty million people inhabit areas of high flare-associated air pollution, which include all of the main ecological zones of the region, indicating that flaring poses a substantial threat to human health and the environment. Model scenarios demonstrated that substantial reductions in pollution could be achieved by stopping flaring at a small number of the most active sites and by improving overall flaring efficiency.

Keywords: Gas Flares, Remote Sensing, Dispersion Modelling, Health Impacts, Environmental Impacts, Niger Delta 


\section{2 \\ 1. Introduction}

A large proportion of Nigeria's oil facilities were developed in the early 1960s and 1970s in response to increased international demand for oil (Rotty, 1974). Gas was not a popular energy source at the time and environmental standards were not as stringent as they are today (Kuranga, 2002 cited in Abdulkareem, 2005a; OGP, 2000), consequently most of the excess gas associated with crude oil production was removed through the process of flaring (Figure 1). This combustion process has been going on for almost six decades in Nigeria, hence its global recognition as a prominent flaring nation (Elvidge et al, 2009).

As there was little local awareness of the environmental impacts of gas flaring in the 1960s and because flaring technology was in its infancy, flaring efficiencies were low relative to modern day standards (Leahey et al., 2001; OGP, 2000) with large volumes of gas flared at flow stations (where oil from different wells is initially gathered) and in refineries on an almost continuous basis (Marais et al., 2014). Although it is generally assumed that flares attain high flaring efficiency, producing only non-toxic carbon dioxide $\left(\mathrm{CO}_{2}\right)$ and water, in reality, combustion is incomplete and harmful by-products such as sulphur dioxide $\left(\mathrm{SO}_{2}\right)$, nitrogen oxides (NOx), hydrogen sulphide $\left(\mathrm{H}_{2} \mathrm{~S}\right)$, volatile organic compounds (VOC), total hydrocarbons, heavy metals and particulates are released into the environment (Johnson and Coderre, 2012; Abdulkareem, 2005a ). Generally, flares are thought to operate at an average efficiency of $68 \% \pm 7 \%$ (Leahey et al., 2001).

[Insert] Figure 1. Open ground flare at Rumuekpe, Rivers State, surrounded by farmland (Ezeamalu, 2014).

The dangers posed by prolonged and continuous flaring have been a source of concern to the inhabitants of the Niger Delta. Reported impacts include increased concentrations of airborne pollutants, reduced agricultural yields, acidification of soils and rainwater, decreased plant flowering and fruiting, corrosion of metal roofs, heat stress, deformities in children, 
decreased lung function and damage, and skin problems (Ismail and Umukoro, 2012). These impacts have prompted numerous studies as documented by Anejionu (2014).

Despite documented negative impacts of air pollution in the region (Tawari and Abowei, 2012; Nwachukwu et al., 2012), there is a paucity of information on the magnitude and extent of air pollution associated with such activities due to weak government regulation and enforcement of environmental standards (Ismail and Umukoro, 2012). This necessitates the requirement for modelling studies to assess the air pollution impacts of gas flaring on the surrounding environment.

Atmospheric dispersion models are commonly used to simulate pollution levels and confirm the ambient concentrations. They can also be used to quantify impacts from individual sources and test scenarios (U.S. EPA, 2011). This study incorporates remotelysensed estimates of emissions from gas flaring in a conventional dispersion model in order to assess the likely air pollution impacts across the Niger Delta over an extended time period. The objectives are as follows:

i. use remotely-sensed inputs to parameterise a conventional atmospheric dispersion model to simulate the flaring process and model the dispersion of pollutants;

ii. use the model to determine how the magnitude and extent of pollution linked to flaring activity have varied over time (including comparisons with established environmental standards);

iii. investigate the contributions from different source sectors (onshore/offshore) and states;

iv. identify candidate sources for emission reduction;

\section{Study Area}

The Niger Delta is at the centre of oil and gas exploration in Nigeria. In addition, it provides the natural habitat for a wide variety of endemic coastal and estuarine fauna and flora, supporting over $60 \%$ of the total species in Nigeria (Anejionu et al., 2015b). It is therefore 
83 ranked as one of the highest conservation priorities in West Africa (IUCN, 1994). The region

84 is very humid with average ambient temperatures ranging from $21^{\circ} \mathrm{C}$ to $35^{\circ} \mathrm{C}$. It generally 85 experiences light south-westerly winds ranging from $1.6 \mathrm{~m} / \mathrm{s}$ to $5.4 \mathrm{~m} / \mathrm{s}$ for most of the year, 86 due to its proximity to the Atlantic Ocean; although during the few dry months of Harmattan 87 (late November to early February), some north-easterly winds are recorded (Marais et al., 88 2014; Odu, 1994).

\section{3. Methodology}

The methodology adopted in this study involves the calculation of emission rates from volume flow rates (estimated from flaring sites detected on satellite images), the use of a conventional atmospheric dispersion model to incorporate flare sources (see section 3.3.2) and consequent verification and modelling of the pollutant concentrations for multiple sources and time periods.

\subsection{Modelling system description}

96 The Atmospheric Dispersion Modelling System (ADMS) comprises a robust group of models 97 developed by Cambridge Environmental Research Consultants (CERC) to simulate dispersion of pollutants from industrial, road, domestic and other sources. ADMS-Urban, used in this research, models emissions from point, line and area sources over large urban

100 areas (CERC, 2011). It has become an integral part of air quality management in the United 101 Kingdom (Arciszewska and McClatchey, 2001) and has been employed in a number of studies including exposure from traffic pollution and more general air quality assessment

103 (Davies and Whyatt, 2014, Abdul-Raheem and Adekola, 2013). It has however not been 104 previously used in combination with remotely-sensed information to model the impact of gas 105 flares. 


\subsubsection{Flare volume flow rate}

109 The volume flow rates used to derive emission rates for each pollutant were obtained from 110 previous research by Anejionu et al. (2015a), who developed techniques to detect active

111 flaring sites and estimate the volume of gas flared from each site from Moderate Resolution

112 Imaging Spectroradiometer (MODIS) satellite imagery (Figure 2). The MODIS Flare

113 Detection Technique (MODET) was developed to detect active flare sites, while the MODIS

114 Volume Estimation Technique (MOVET) was used to estimate the annual quantity of gas

115 flared from individual flare sites based on radiation detected from such sites. These

116 techniques were used to determine the location of active flare sites and volume flow rates

117 included in the modelled assessment.

118

119

120

121

122

123

124

[Insert] Figure 2. The total volume of gas combusted at individual flare sites in the Niger Delta (2000-2014), reproduced from Anejionu et al., (2015a).

\subsubsection{Meteorological data}

Historic meteorological data (wind speed, wind direction, ambient temperature and cloud cover) were obtained from a weather data archive (Weather Underground, 2013). Given the limited hourly meteorological data for Port Harcourt and other weather stations in the region, hourly data for a neighbouring country (Malabo, Equatorial Guinea) in the Atlantic Ocean (Figure 2), were utilised. The hourly data did not include rainfall amount, hence, mean monthly rainfall values and rainfall days for the Niger Delta (Climate Charts, 2010; Norwegian Meteorological Institute, 2014) were used to compute hourly rainfall values for each month.

\subsubsection{Emission factors}

There are practical challenges in obtaining accurate estimates of emissions associated with flaring (OAQPS, 1984; Backshall, 2013). As a result, predetermined emission factors are 
133 typically used to compute emission rates for flares. The emission factors relate the quantity of

134 a pollutant released with an activity associated with the release of that pollutant (e.g. amount

135 of gas flared per unit time) (U.S. EPA, 2014a). The emission factors adopted in the study

136 (Table 1) were established by the UK Department of Energy and Climate Change (EEMS,

137 2008) and are similar to those recommended by the Exploration and Production Forum (E\&P

138 Forum, 1994).

139 [Insert] Table 1. Emission factors used in the modelling. The units for the emission factors are 'mass of

140 pollutant per unit mass of flared gas’. (Source: EEMS, 2008; E\&P Forum, 1994).

3.3 Methods

\subsubsection{Computing gas flare emission rates}

144 The following equation for estimating emission rates taken from OAQPS (1995) and Ontario

145 (2007) was used to calculate pollutant emissions:

$$
E=A * E F *(1-E R / 100)
$$

Where: $\mathrm{E}$ is the emission rate of a pollutant $(\mathrm{g} / \mathrm{s}), \mathrm{A}$ is the activity rate $(\mathrm{g} / \mathrm{s})$ which is the mass of gas flared, EF is emission factor of a pollutant, and ER is the overall emission reduction efficiency (flaring efficiency in \%). Flaring efficiency of $75 \%$ was assumed for flares in the Niger Delta based on findings of earlier studies (Leahey et al., 2001; Sawaragi and Akashi, 1978 cited in Abdulkareem, 2005a). Ismail and Umukoro (2012) stated that "on a casual observation of the flares in the Niger Delta one sees that they are sooty and evidently burn at low efficiency.” Flaring efficiency is thus used in this context as a primary measure of the overall performance of the flare systems and not necessarily as the combustion efficiency, which relates to the percentage of the natural gas that is completely oxidized to $\mathrm{CO}_{2}$ and water (US. EPA, 1983).

The volume of gas flared (in $\mathrm{m}^{3} /$ year) from each flare site was estimated from remote sensing (Anejionu et al., 2015a). This was converted to a mass flow rate (g/s) assuming that 
159 the flared gas has the density of methane (the dominant component of the gas extracted in the

160 Niger Delta (Isichei and Sanford, 1976).

161

162

163

164

165

166

167

168

169

170

171

172

173

174

175

176

177

178

179

180

181

182

183

184

\subsubsection{Computation of effective diameter and height}

Gas is typically flared from stacks of fixed height and diameter, however actual combustion occurs beyond the tip of the flare stacks (Figure 3). As a result, flare stack parameters such as effective height and diameter are calculated to account for this.

Effective stack height is calculated as the sum of the stack height and the height of the flame above the stack exit point to the flame tip. The effective diameter is derived from the flare buoyancy flux. To compute the effective height $\left(\mathrm{H}_{\text {eff }}\right)$ and effective diameter $\left(D_{\text {eff }}\right)$, various factors such as heat release are required to compute flame buoyancy and height increase (see section 3.3.2.1 for details).

[Insert] Figure 3. Effective stack height and diameter (Price, 2013).

\subsubsection{Details of computation of flaring parameters}

Heat released was computed using the following expression (San Joaquin Valley APCD, 2014).

$$
\mathrm{Q}=(\mathrm{W} / 3.6) * \sum \mathrm{w}_{\mathrm{i}} \mathrm{q}_{\mathrm{i}}
$$

Where: Q is heat released per hour $(\mathrm{kW}), \mathrm{W}$ is gas flow rate $(\mathrm{kg} / \mathrm{hr}), \mathrm{w}_{\mathrm{i}}$ is mass fraction of component $\mathrm{i}$, and $\mathrm{q}_{\mathrm{i}}$ is heating value of gas component $\mathrm{i}(\mathrm{MJ} / \mathrm{kg})$. The methane heating value of $55.53 \mathrm{MJ} / \mathrm{kg}$ was used.

The heat released was further converted from $\mathrm{kW}$ to $\mathrm{J} / \mathrm{s}$, and the net heat released in $\mathrm{J} / \mathrm{s}$ $\left(Q_{n}\right)$ computed by assuming a $25 \%$ heat loss (recommended as default) by Ontario Ministry of Environment (2003) using:

$$
\mathrm{Q}_{n}=(75 / 100) * \mathrm{Q}_{\mathrm{j}}
$$

The height increase $(\Delta \mathrm{h})$ was computed using the following equation: 
186

187

188

189

190

191

192

193

194

197

198

199

200

201

202

203

204

205

206
Where Qc is the net heat release in units of calories/s.

Subsequently, the effective height $\left(\mathrm{H}_{\text {eff }}\right)$ is computed as:

$$
\mathrm{H}_{\text {eff }}=\mathrm{H}+\Delta \mathrm{h}
$$

Where $\mathrm{H}$ is the measured stack height.

The flare buoyancy flux $\left(F_{b}\right)$ in turn was computed using the following expression:

$$
F_{\mathbf{b}}=\frac{g^{*} \mathrm{Q}_{\mathrm{n}}}{\pi^{*} \rho^{*} T_{a}{ }^{*} \mathrm{Cp}}
$$

Where $\mathrm{g}$ is acceleration due to gravity $\left(\mathrm{m} / \mathrm{s}^{2}\right), \rho$ is air density $\left(\mathrm{kg} / \mathrm{m}^{3}\right), T_{a}$ is air temperature $(\mathrm{K})$ and $C_{p}$ is the specific heat of dry air $(\mathrm{J} /(\mathrm{kg} \mathrm{K})$. The flare buoyancy flux was subsequently used to compute the effective diameter ( $D_{\text {eff }}$ ), using the following expression:

195

$$
\mathrm{D}_{\text {eff }}=\left(\frac{\left.2\left(F_{b}\left(\frac{T_{f}}{\left(T_{f}-T_{a}\right.}\right)^{96}\right)\right)}{(g v)^{0.5}}\right)
$$

Where $T_{f}=$ flare exit temperature and $\mathrm{v}=$ the stack exit velocity. Flare exit temperature of $1,273 \mathrm{~K}\left(1000^{\circ} \mathrm{C}\right)$, which matches those in the region (Abdulkareem, 2005a) and exit velocity of 20m/s (U.S EPA, 1995; Ontario Ministry of Environment, 2003) was used.

\subsubsection{Pollutant concentration verification}

As noted by Marais et al. (2014), there is a paucity of monitored air pollution data for the Niger Delta. However, we were able to use a spatially and temporally limited set of ambient monitoring data (Osuji and Avwri, 2005) for the purposes of model verification. The monitoring sites were used as receptors, and modelled concentrations were compared to observed concentrations at each site. 
The model input and setup were initially verified for a single source (flare) using lower,

208 central and upper volume estimates from the MODIS volume estimation technique

209 (Anejionu, 2015a). The resulting concentration profiles were similar to those reported by

210 Abdulkareem (2005b), with peak concentrations occurring 500m - 600m downwind of the

211 source (Supplementary Figure 1). Subsequently, the verification was extended to other sites

212 within the region.

213 A binary validation matrix was computed and Factor-2 analysis conducted

214 (Supplementary Tables 1 and 2). In addition, a semi-quantitative approach using data from

215 the satellite-based Scanning Imaging Absorption Spectrometer for Atmospheric Cartography

216 (SCIAMACHY) was used to guide the verification process. This semi-quantitative approach,

217 which effectively indicated an upper limit for the modelled estimates was used in conjunction

218 with the Factor-2 matrix to select the most appropriate modelling parameters including

219 volume flow rates (low, medium and high estimates) and background ozone concentration

220 (Vingarzan, 2004). Marais et al., (2014) similarly used satellite (including SCIAMACHY) and aircraft observations of atmospheric and tropospheric column-integrated concentrations to verify atmospheric composition over Nigeria produced by a chemical transport model. Consequently, lower estimates of flaring volumes were used with a background ozone concentration of $10 \mu \mathrm{g} / \mathrm{m}^{3}$ in the modelling (see Supplementary Tables 1 \& 2).

\subsubsection{Modelling gas flare pollutant concentrations}

Having verified the method and determined the relevant model parameters ADMS-Urban was used to model the dispersion of flare-related pollutants $\left(\mathrm{NO}_{2}, \mathrm{SO}_{2}, \mathrm{CO}\right.$ and $\left.\mathrm{O}_{3}\right)$ across the Niger Delta for the period 2000 to 2013 inclusive. To establish a baseline for the modelling, various scenarios representing typical and possible conditions in the region were simulated. About half of the flares in the region are thought to be ground flares (open and horizontallydirected flares lying about $1.5 \mathrm{~m}$ above the ground - Figure 1) with the remainder thought to

232 be short stacks (10m above the ground) (Dung et al., 2008; Isichei and Sanford, 1976). As 
we have no official information on flare locations and heights, sensitivity to model stack

234 height was tested by assuming all flares were ground-based in one scenario and released from 235 15m stacks in another. Pollutant concentrations across the region did not vary significantly 236 between scenarios (about $1 \mu \mathrm{g} / \mathrm{m}^{3}$ difference) hence a height of $10 \mathrm{~m}$ was adopted for all the 237 flares included in the study.

238 A variable surface roughness file was implemented to account for onshore and offshore environments with values of $0.3 \mathrm{~m}$ and $0.001 \mathrm{~m}$ adopted for land and sea areas accordingly.

240 Chemical reactions between the primary pollutants and the atmosphere were modelled to obtain secondary pollutants $\mathrm{NO}_{2}$ and $\mathrm{O}_{3}$ from $\mathrm{NO}_{\mathrm{x}}$ and VOC. Wet and dry deposition was also modelled.

\subsubsection{Spatial modelling and analysis of pollutant concentration}

The results of the modelling were incorporated within a Geographical Information System (GIS). This enabled pollution estimates to be integrated with other spatial data for the region including flare locations, state boundaries, ecological zones and population data. The GIS also facilitated the investigation of contributions from onshore and offshore flares, as well as individual states. WHO Air Quality Limits (Table 2) were used to delineate areas of risk.

\section{Results}

Figure 4 illustrates the spatial distribution of modelled pollutant concentrations across the Niger Delta region for the representative year 2000. This year was chosen because emissions in 2000 were higher than present day levels but lower than those experienced in 2005 and 2006. Results are presented for $\mathrm{NO}_{2}$ and $\mathrm{O}_{3}$ since these are key pollutants that affect human and plant health. Other pollutants showed similar overall patterns of dispersion. 
States with few (Imo and Abia) or no (Enugu and Cross River) active flare sites experienced higher levels of pollution than states containing multiple active flare sites

264 (Bayelsa, Rivers and Delta) due to the predominant south-westerly wind in the region. Imo,

265 Akwa Ibom, Abia and some parts of Rivers State experienced the highest levels of pollution overall with annual mean concentrations of $\mathrm{NO}_{2}$ and $\mathrm{O}_{3}$ exceeding $\mathrm{WHO}$ annual limits (Table 2) in some years (Figure 5). Limits for other pollutants such as $\mathrm{CO}$ and $\mathrm{SO}_{2}$ were not exceeded.

Figure 5 illustrates mean $\mathrm{NO}_{2}$ concentration across the region for the period 2001-2013. Concentrations (of all pollutants) increase to a peak in 2005/2006 before declining to the present day. This trend is consistent with crude oil production in Nigeria over this period and with increased gas flaring noted by Anejionu et al., (2014, 2015a). These findings are consistent with statements from the oil and gas companies in the region regarding reduced flaring activities (SPDC, 2013).

[Insert] Figure 5. Modelled time series of annual mean $\mathrm{NO}_{2}$ concentrations across the Niger Delta (2000 2013). Areas of highest concentration exceed the WHO limit of $40 \mu \mathrm{g} \mathrm{m}^{-3}$ order to determine relative and absolute contributions on a state-by-state basis. The results reveal that the majority of air pollution is generated by onshore sources (Figure 6) and that the impact of offshore flares is negligible. However, a significant (>30\%) proportion of air pollution received by Akwa Ibom State and to a lesser extent the coastal areas of Bayelsa and Delta States, originates from offshore sources, because a lot of flaring activity takes place just off the coast of Akwa Ibom (Figure 2).

[Insert] Figure 6. Modelled annual mean $\mathrm{NO}_{2}$ concentration across the Niger Delta in 2000 revealing specific pollution contributions from offshore and onshore source sectors. Note: The sum of source sector contributions does not equate to modelled total concentration (all flares) due to non-linearities in the $\mathrm{NO}_{2}$ chemistry.

In order to determine inter-state contributions to pollutant concentrations across the region, the model was run 8 times using emissions from each flaring state in turn. The 
concentrations produced from each run were aggregated for each receiving state and

292 statistically summarised. The resulting 'blame matrix' for $\mathrm{NO}_{2}$ is shown in Table 3. Analysis

293 of the 'blame matrix' revealed Rivers State to be the largest single contributor to air pollution

294 in many states, exporting more pollution to Abia, Imo and Akwa Ibom, than it generated

295 locally. Other states, which are not officially classed as oil-producing, such as Enugu,

296 Anambra, Cross River and Ebonyi, also experienced high concentrations. Approximately 20

297 million people live in the towns and cities of these densely populated states (NPC, 2010) and

298 are exposed to high levels of pollution from sources beyond their immediate control.

299

300

301

302

303

304

305

306

307

308

309

310

311

313

314

315

316

317

318

319
[Insert] Table 3. Blame matrix using mean $\mathrm{NO}_{2}$ concentration $\left(\mu \mathrm{g} / \mathrm{m}^{3}\right)$ for the year 2000 data to illustrate the pollutant contribution of individual states on neighbours.

Figure 7 illustrates the potential impact of air pollution on major population centres in and around the Niger Delta in addition to impacts on vegetation and ecosystems. Major towns and cities such as Enugu, Aba and Calabar all experienced high levels of pollution in 2005/06, while others such as Port Harcourt, Benin City and Warri experienced much lower levels in comparison. Elevated ozone levels were found across the Niger Delta, suggesting significant harmful impacts on plants in all ecological zones (Figure 7c and Table 4). The rainforest was found to be the most susceptible to damage with $51 \%$ of this zone being exposed to high ozone levels (Table 4). This is important not only for the natural ecosystem, but because the majority of farming in the region is carried out within this zone, implying strong negative impacts on biodiversity and agriculture. The freshwater swamp, mangrove and savannah zones were also heavily impacted by secondary pollutants, with moderate or high ozone levels being experienced over 58\%, 33\% and 43\% of their areas, respectively.

[Insert] Table 4. Modelled impacts $\left(\mathrm{km}^{2}\right)$ of ozone on main ecological zones in the Niger Delta in 2005.

[Insert] Figure 7. Modelled impacts of $\mathrm{NO}_{2}$ and $\mathrm{O}_{3}$ on human health and natural ecosystems. Maps show: (a) $\mathrm{NO}_{2}$ concentration (b) $\mathrm{NO}_{2}$ concentration in relation to underlying population (c) $\mathrm{O}_{3}$ concentration and (d) $\mathrm{O}_{3}$ concentration in relation to underlying ecological zones. 2005 results were used in this case to illustrate maximum impact. 
Figure 8 illustrates the spatial distribution of pollutant deposition. In contrast to the

321

322

323

324

325

326

327

dispersion of gases such as $\mathrm{NO}_{2}$, patterns of wet and dry deposition are much more localised within the main flaring areas.

[Insert] Figure 8. Map showing annual rates of total (wet + dry) deposition across the Niger Delta, 2000.

To understand the extent to which present day levels of air pollution could be reduced further in the region the model was re-run using 2013 sources with assumed flaring efficiencies of $85 \%$ and $95 \%$ respectively. The results are summarised in Table 5.

[Insert] Table 5. Statistical summary of pollution surfaces obtained using different flaring efficiencies tested based on 2013 emissions $\left(\mu \mathrm{g} / \mathrm{m}^{3}\right)$. Percentage improvements were obtained by subtracting the pollutant concentrations for $95 \%$ efficiency from the corresponding $75 \%$ efficiency, and using the difference to calculate percentage improvement from $75 \%$ concentration levels.

\section{Discussion}

In this study, the gas flaring process was implemented within a conventional dispersion model using emission estimates derived from remotely-sensed imagery. The results suggest that gas flaring remains a major contributor to air pollution across the region with states containing few or no active flare sites often experiencing higher levels of pollution than states actively involved in the flaring process (Figures 4 and 7). This large dispersion range may be explained by the high momentum and buoyancy of the flare plumes. This is important because prior to this finding, it has always been assumed that the effects of gas flaring were highly localised in nature (Ovri and Iroh, 2013; Dung et al., 2008; Isichei and Sanford, 1976). Consequently, fiscal intervention and compensation from the Federal Government of Nigeria to cushion the effects of environmental degradation resulting from oil exploration activities such as gas flaring has not been extended to the non-oil-producing states. The findings from this research provide clear evidence justifying the need for the revision of such compensatory policies.

The pollution risk maps (Figure 5) revealed that major towns and cities located some distance from major flaring activity have experienced pollutant levels in excess of WHO 
limits, while towns in prominent flaring states, have experienced much lower levels in comparison. It should, however, be noted that although some major cities (Warri and Benin

351 City) were found not to be among the very high risk areas, pollution from other sources

352

353

354

355

356

357

358

359

360

361

362

363

364

365

366

367

368

369

370

371

372

373

374

375

376

(transport and industry) could lead to exceedance of WHO limits. Analysis of the modelled deposition (Figure 8) revealed that Rivers State was at the greatest risk of acid deposition, followed by Akwa Ibom. This corroborates previous studies, where rainwater was found to be acidic around flaring locations (Ovri and Iroh, 2013; Ekpoh and Obia, 2010, Nduka et al., 2008).)

Analyses of results obtained from a model scenario of increasing flaring efficiency (Table 5), based on simple treatment of emissions (Equation 1), suggest that significant improvements in air quality could be achieved by increasing the flaring efficiency of sites in the region. Even at 85\% flaring efficiency, no part of the region would experience pollution levels exceeding the WHO standards.

The results obtained from modelling a hypothetical scenario in which emissions were suppressed at some of the most active flaring sites in the region revealed that the proportion of pollution generated by these flares was relatively high compared to that generated by the remaining flares in the region (Table 6) with $27 \%$ of the pollution in the study area (and much higher proportions in some states) generated by only 14 out of the 103 active flares. This suggests that air quality in the Niger Delta could be improved further through targeted interventions of selected sources.

[Insert] Table 6. The impact of suppressing emissions from the 14 largest flaring sites in the region (2013). Note: the sum of concentrations from the 14 largest sites and the other sites does not equate to corresponding modelled concentrations for all flares due to non-linearities in the $\mathrm{NO}_{2}$ chemistry

Whilst the outcomes of this research cast an interesting light on the environmental impacts of gas flaring in the Niger Delta, it should be acknowledged that the results presented are illustrative as opposed to definitive, with large uncertainty bounds. In this study we had limited access to hourly meteorological data from the region, no reliable information on 
emission rates, limited information on flare stack heights and limited ambient monitoring

378 data for verification purposes. Despite these limitations, which may affect the absolute 379 accuracy of our results, this study does provide important insights into the impacts of flaring on local and regional air pollution. It has shown the value of combining flaring volume estimates from remotely-sensed data with emission factors to generate credible emission rates that can be employed in a dispersion model. Given the lack of official information on pollutant concentrations in the region, these model estimates are invaluable. We expect that our results will serve as a guide to researchers, who now have some empirical basis with which to underpin their observations of flaring impacts. It may also catalyse the release of monitored data by multinational companies operating in the region and prompt further research. The results may also result in policy changes, as state governments in the high risk areas who are not receiving commensurate compensations from the Federal Government could base their arguments on the findings of this research. It is also our expectation that techniques developed in the research will play significant role in the future monitoring and management of air quality in the Niger Delta. Based on the modelled time-series, we have shown that pollutant concentrations are now declining across the region as flaring activities are reduced, but we have also demonstrated that further improvements in air quality can be achieved through the adoption of more efficient flaring technologies.

\section{Conclusion}

This research pioneered the use of emission information derived from remotely-sensed data in estimating air pollution linked to gas flaring in the region. The results indicate the likely magnitude and extent of pollution across the region associated with the gas flaring process.

400 We hope that the results from this study will prompt the release of more flaring information, 401 leading to better source characterisation and further refinement of the modelling process. 

and continues to be, a major influence on air pollution in the region. Since flaring has been practiced for close to 60 years, the environmental and health impacts are likely to have been significant. Looking forwards, future impacts can be minimised with improved flaring efficiency and suppression of flaring activity from some of the larger sites.

\section{Acknowledgements}

We wish to acknowledge the Petroleum Technology Development Fund (PTDF Nigeria) who

(SURCON), who partly supported the initial stages of this project with a research grant, and

the Department of Geoinformatics and Surveying, University of Nigeria Enugu Campus, for

Carruthers (CERC) for his invaluable feedback and acknowledge the free use of tropospheric

$\mathrm{NO}_{2}$ column data from the SCIAMACHY sensor from www.temis.nl.

\section{References}

417

418

419

420

421

422

423

424

425

426

427

428

429

430

431

432

433

434

435

436
Abdulkareem, A. S. (2005a). Evaluation of ground level concentration of pollutant due to gas flaring by computer simulation: A case study of Niger - Delta area of Nigeria.

Abdulkareem, A. S. (2005b). Urban air pollution evaluation by computer simulation: A case study of petroleum refining company Nigeria. Leonardo Journal of Sciences, 6, 17-28

Abdul-Raheem, A.M.O. and Adejola, F.A. (2013). Variation of source distribution of total oxidants: Contributions of oxides of nitrogen, sulphur (IV) oxide emissions and background ozone from Lagos-Nigeria. International Journal of Physical Sciences, 8 (11), 411-420.

Anejionu, O.C.D. (2014). Remote survey of gas flares and associated environmental and health impacts in the Niger Delta. PhD thesis submitted to the Lancaster University.

Anejionu, C.D.O., Blackburn, G.A., and Whyatt, J.D. (2014). Satellite survey of gas flares: development and application of a Landsat-based technique in the Niger Delta. International Journal of Remote Sensing, 35(5), 1900-1925.

Anejionu, C.D.O., Blackburn, G.A., and Whyatt, J.D. (2015a). Detecting gas flares and estimating flaring volumes at individual flow stations using MODIS data. Remote Sensing of Environment, 158, 81-94.

Anejionu, O.C.D. Ahiarammunnah, P.A.N., and Nri-ezedi, C.J. (2015b). Hydrocarbon pollution in the Niger Delta: Geographies of impacts and appraisal of lapses in extant legal framework. Resources Policy, 45, 65-77.

Arciszewska, C. and McClatchey, J. (2001).The importance of meteorological data for modelling air pollution using ADMS-Urban. Meteorological Application Journal, 8, 345-350. 
Backshall, D. (2013). Atmospheric dispersion modelling of discharges to air from the flaring of fracturing fluid. Prepared for Taranaki Regional Council by Air Quality Management Ltd. Report Number 13-008.

Boersma, K.F., Eskes, H.J., and Brinksma, E.J. (2004). Error Analysis for Tropospheric NO2 Retrieval from Space. Journal of Geophysical Research. 109 (D04311), 1-20.

CERC (Cambridge Environmental Research Consultants). (2011). ADMS-Urban: An urban air quality management system. User Guide -Version 3.1.

Climate Charts (2010). Port Harcourt, Nigeria: Climate, Global Warming, and Daylight Charts and Data. http://www.climate-charts.com/Locations/n/NI65250.php (accessed 17th December, 2013).

Davies, G., and Whyatt, J.D. (2014). A network-based approach for estimating pedestrian journeytime exposure to air pollution. Science of the Total Environment (485-486), $62-70$.

Dung, E.J., Bombom, L.S., Agusomu, T.D. (2008). The effects of gas flaring on crops in the Niger Delta, Nigeria. GeoJournal, 73, 297-305.

E\&P Forum (Exploration and Production Forum). (1994). Methods for estimation of atmospheric emissions from E\&P Operations. The Oil Industry International Exploration and Production Forum Report No 2.59/197.

EEMS (Environmental Emissions Monitoring System). (2008). Atmospheric Emissions Calculations. https://www.gov.uk/government/uploads/system/uploads/attachment data/file/136461/atmoscalcs.pdf (accessed 17th December, 2013).

Ekpoh, I.J. and Obia, A.E. (2010).The role of gas flaring in the rapid corrosion of zinc roofs in the Niger Delta Region of Nigeria. Environmentalist, 30, 347-352.

Elvidge, C.D., Ziskin, D., Baugh, K.E., Tuttle, B.T., .Ghosh, T., Pack, D.W., Erwin, E.H \& Zhizhin, M. (2009). A fifteen year record of global natural gas flaring derived from satellite data. Energies, 2., 592-622.

Ezeamalu, B. (2014). Investigation: How decades of gas flaring is harming Nigerians (Part 1). Premium Times Newspaper. http://www.premiumtimesng.com/news/160899-investigationdecades-gas-flaring-harming-nigerians-part-1.html (accessed 17th May, 2014).

Isichei, A.O., and Sanford, W.W. (1976). The effects of waste gas flares on the surrounding vegetation in South- Eastern Nigeria. Journal of Applied Ecology, 13 (1), 177-187.

Ismail, O.S. and Umukoro, G. E. (2012). Global Impact of Gas Flaring. Energy and Power Engineering, 4, 290-302.

IUCN (International Union for the Conservation of Nature). (1994). A Guide to the Convention to the Biological Diversity. Environmental Policy and Law Paper, No. 30. https://portals.iucn.org/library/efiles/documents/EPLP-no.030.pdf (Accessed 10 ${ }^{\text {th }}$, December, 2011).

Johnson, M.R. and Coderre, A.R. (2012). Compositions and Greenhouse Gas Emission Factors of flared and vented Gas in the Western Canadian Sedimentary Basin, Journal of the Air \& Waste Management Association, 62(9):992-1002.

Leahey, D.M. Preston, K., Strosher, M. (2001). Theoretical and Observational Assessments of Flare Efficiencies. Journal of the Air and Waste Management Association, 51, 1610-1616.

Marais, E.A., Jacob, D.J., Wecht, K., Lerot, C., Zhang, L., Yu , K., Kurosu, T.P., Chance, K., and Sauvage, B. (2014). Anthropogenic emissions in Nigeria and implications for atmospheric ozone pollution: A view from space. Atmospheric Environment, 99, 32-40.

Nigeria Population Commission. (2010). 2006 population and housing census: Population distribution by state, LGA, and senatorial districts. http://www.ibenaija.org/uploads/1/0/1/2/10128027/vol_03_table_dsx_lgapop_by_sdistrictpdf.pdf (accessed 15th June, 2013).

Norwegian Meteorological Institute (2014). Weather statistics for Port Harcourt, Rivers (Nigeria). http://www.yr.no/place/Nigeria/Rivers/Port Harcourt/statistics.html (accessed 17th December, 2013).

Nwachukwu A. N., Chukwuocha E. O., and Igbudu O. (2012). A survey on the effects of air pollution on diseases of the people of Rivers State, Nigeria. African Journal of Environmental Science and Technology 6(10), 371-379.

Nduka, J.K.C., Orisakwe, O.E., Ezenweke, L.O., Ezenwa, T.E., Chendo, M.N., and Ezeabasili, N.G. (2008). Acid Rain Phenomenon in Niger Delta Region of Nigeria: Economic, Biodiversity and Public Health Concern. The Scientific World Journal, 8, 811-818. 
OAQPS (U.S. EPA Office of Air Quality Planning and Standards). (1984). Evaluation of the efficiency of industrial flares. http://www.tceq.state.tx.us/assets/public/implementation/air/rules/Flare/Resource 2.pdf (accessed on 20th March, 2014)

OAQPS (U.S. EPA Office of Air Quality Planning and Standards). (1995). Compilation of air pollution emission factors: Volume 1 - stationary points and area sources. AP 42 document. http://www.epa.gov/ttn/chief/ap42/index.html (accessed $19^{\text {th }}$ February, 2014).

Odu, C. T. I. (1994). Gas flare emissions and their effects on the acidity of rain water in the Ebocha area. https://www.elaw.org/system/files/Ng.GasFlares.AcidRain.Ebocha.doc (accessed $9^{\text {th }}$ March, 2013).

OGP (International Association of Oil and Gas Producers). (2000). Flaring and venting in the oil and gas exploration and production industry: An overview of purpose, quantities, issues, practices and trends. Report No. 2.79/288. http://www.ogp.org.uk/pubs/288.pdf (accessed $14^{\text {th }}$ January, 2014).

Ontario Ministry of the Environment. (2003). Proposed guidance for air dispersion modelling. http://www.weblakes.com/products/aermod/resources/Ontario_MOE_Proposed_Air_Dispersio n_Modelling Guidance.pdf (accessed $19^{\text {th }}$ February, 2014).

Ontario Ministry of the Environment. (2007). Step by step guideline for emission calculation, record keeping and reporting for airborne contaminant discharge. (accessed $14^{\text {th }}$ April, 2014).

Osuji, L.C., and Avwiri GO (2005). Flared Gases and Other Pollutants Associated with Air Quality in Industrial Areas of Nigeria: An Overview. Chemistry and Biodiversity, 2, 1-8.

Ovuakporaye, S.I., Aloamaka, C.P., Ojieh, A.E., Ejebe, D.E., and Mordi, J.C. (2012). Effect of gas flaring on lung function among residents in gas flaring community in Delta State, Nigeria. Research Journal of Environmental and Earth Sciences 4(5): 525-528.

Price, C. (2013). Modelling flares in ADMS 5. Presented at ADMS 5 User Group Meeting at The Assembly Rooms, Newcastle ( $13^{\text {th }}$ November).

Rotty R.M. (1974). First estimates of global flaring of natural gas. Atmospheric Environment, 8, 681-686.

San Joaquin Valley Air Pollution Control District. (2014). http://www.valleyair.org/busind/pto/Resources/Modeling/Source\%20Parameters/Flare\%20Mod eling\%20Parameters.xlsx (accessed 19th January, 2014).

SPDC (Shell Petroleum Development Company of Nigeria). (2013). Shell in Nigeria: Gas Flaring. http://s02.static-shell.com/content/dam/shell-

new/local/country/nga/downloads/pdf/2013bnotes/gas-flaring.pdf (Accessed 9th, March, 2014).

Tawari, C.C. and Abowei, J.F.N. (2012). Air Pollution in the Niger Delta Area of Nigeria. International Journal of Fisheries and Aquatic Sciences 1(2), 94-117.

U.S. EPA (United States Environmental Protection Agency). (2011). Dispersion modelling. http://www.epa.gov/air/aqmportal/management/modeling/dispersion.htm (accessed 4th October, 2013).

U.S. EPA (United States Environmental Protection Agency). (2014a). Emissions Factors \& AP 42, Compilation of Air Pollutant Emission Factors. http://www.epa.gov/ttn/chief/ap42/index.html (accessed 21st February, 2014).

U.S. EPA (United States Environmental Protection Agency). (2014b) National Ambient Air Quality Standards (NAAQS). http://www.epa.gov/air/criteria.html

Vingarzan, R. (2004). A review of surface ozone background levels and trends. Atmospheric Environment, 38, 3431-3442.

Weather Underground. (2013). Weather History for Malabo, Equatorial Guinea. http://www.wunderground.com/history/airport/FGSL (accessed $12^{\text {th }}$ December, 2013).

WHO (World Health Organisation). (2005). WHO Air quality guidelines for particulate matter, ozone, nitrogen dioxide and sulfur dioxide. Global Update. Summary of risk assessment. WHO/SDE/PHE/OEH/06.02. 
Figure 1

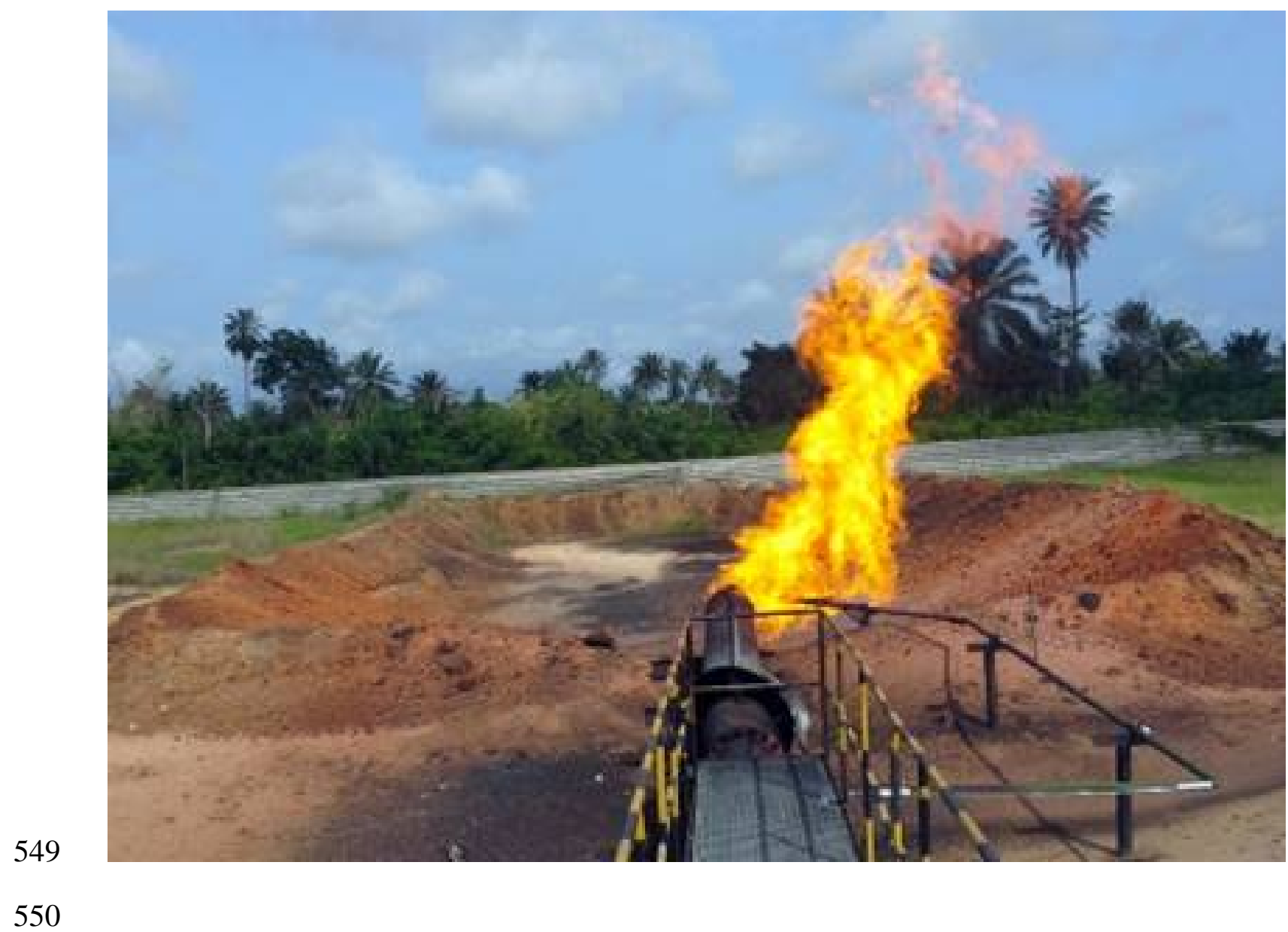

551

552

553

554

555

556

557

558

559

560

561

562 
Figure 2

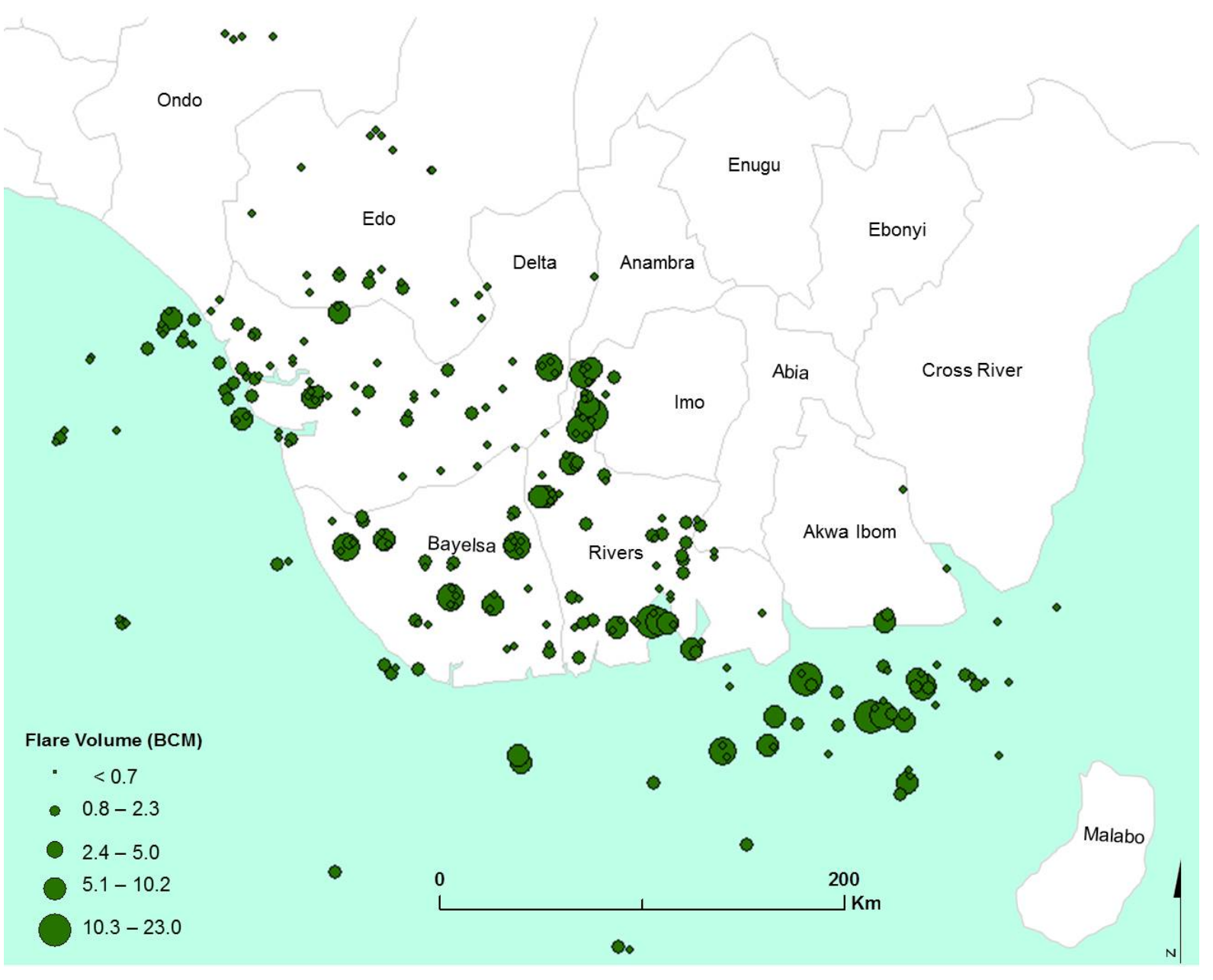

565

566

567

568

569

570

571

572

573

574

575

576 
Figure 3

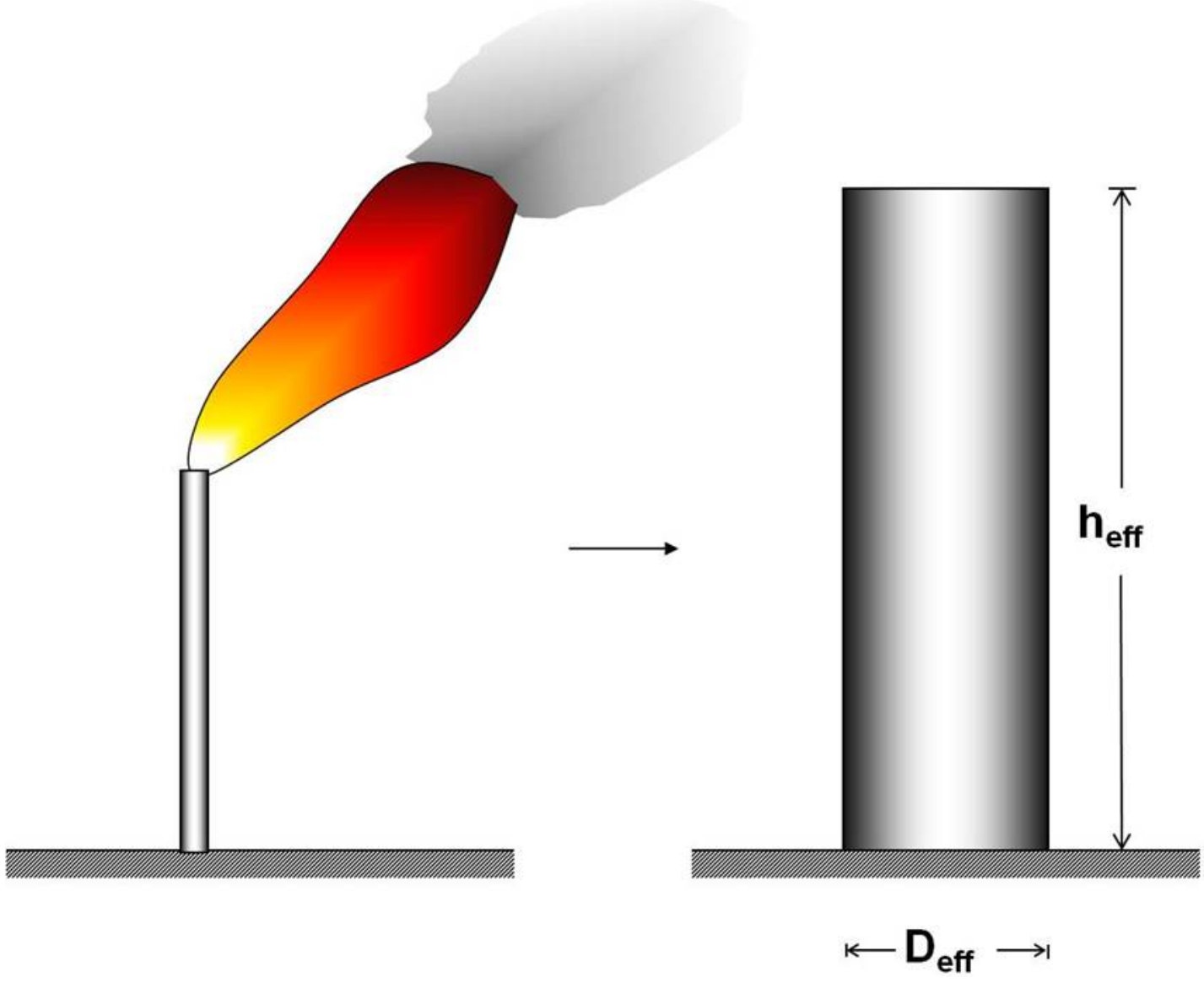

578

579

580

581

582

583

584

585

586

587

588

589

590 
Figure 4

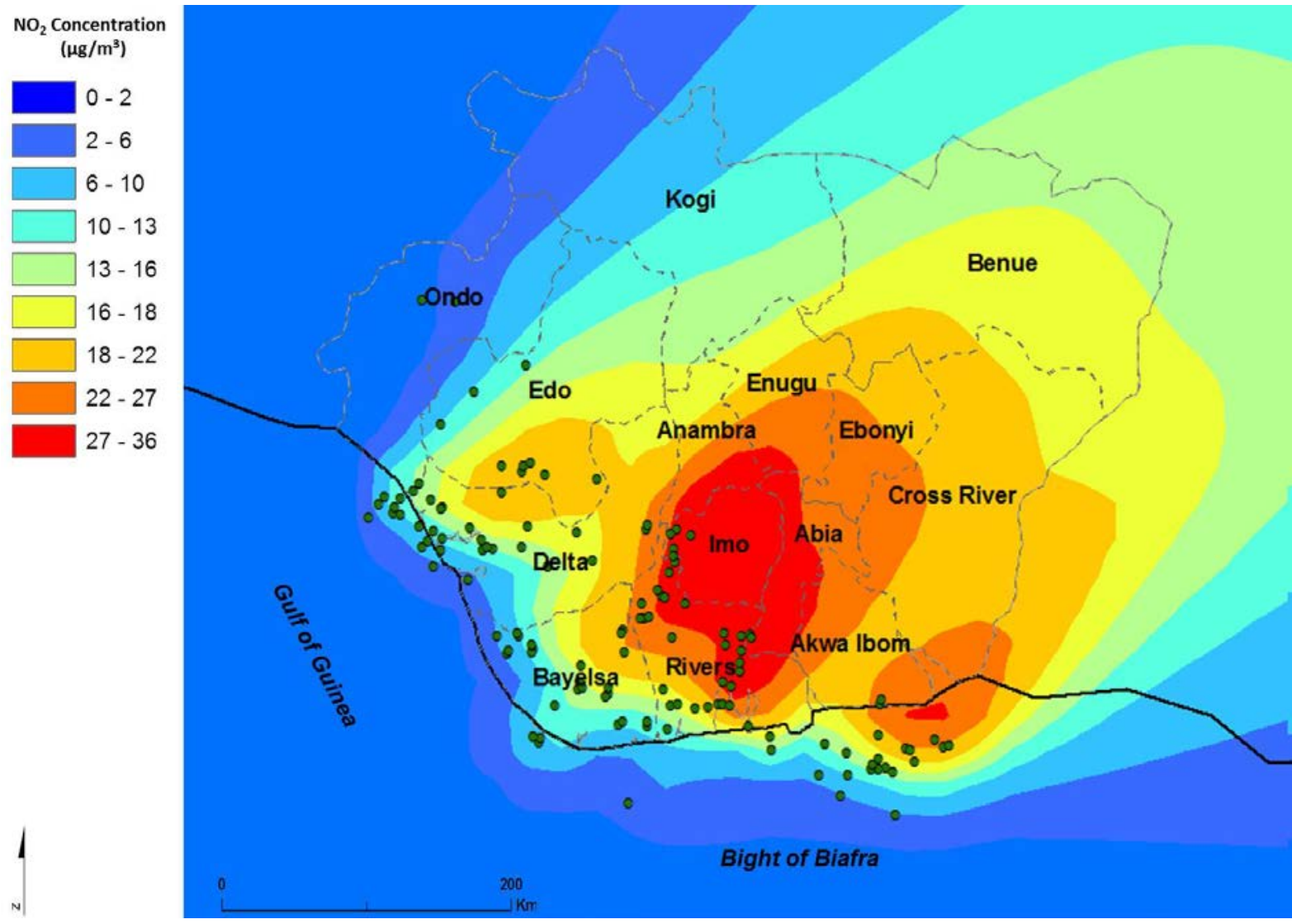

593

594

595

596

597

598

599

600

601

602

603

604

605 
Figure 5
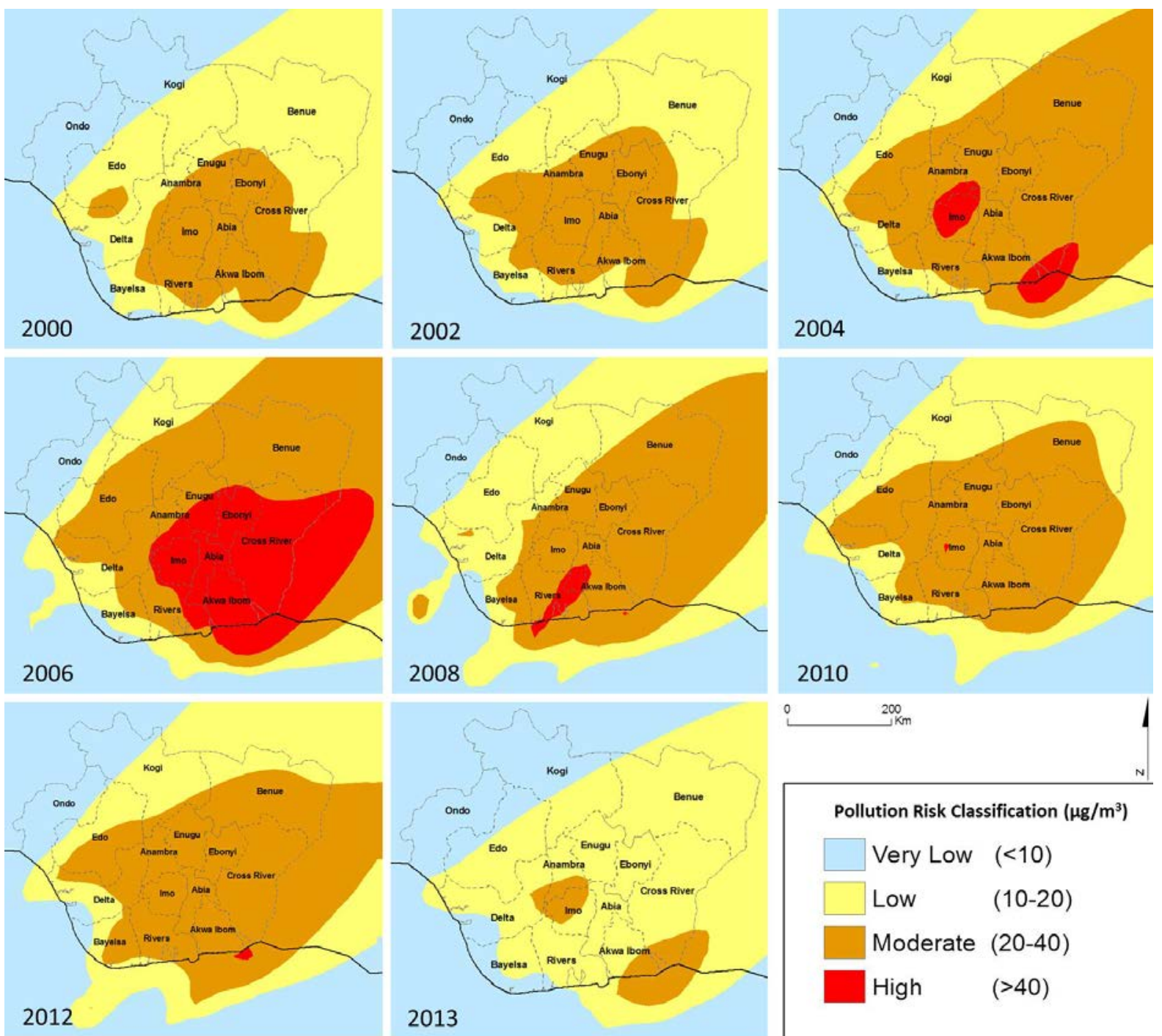

Pollution Risk Classification $\left(\mu \mathrm{g} / \mathrm{m}^{3}\right)$

\begin{tabular}{|c|c|}
\hline Very Low & $(<10)$ \\
\hline Low & $(10-20)$ \\
\hline Moderate & $(20-40)$ \\
\hline
\end{tabular}

High $\quad(>40)$ 
Figure 6
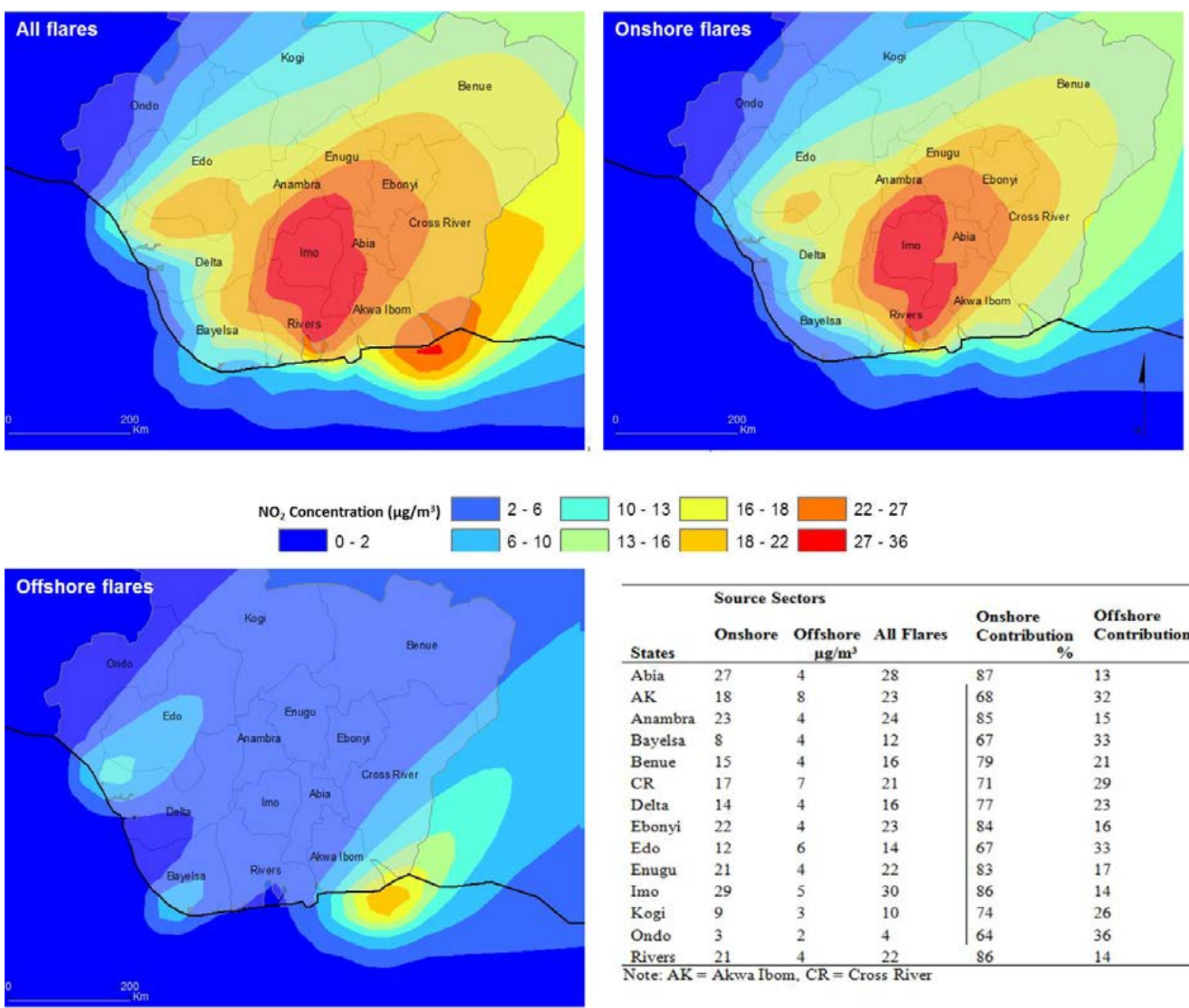

\begin{tabular}{|c|c|c|c|c|c|}
\hline \multirow[b]{2}{*}{ States } & \multicolumn{3}{|c|}{ Source Sectors } & \multirow[b]{2}{*}{$\begin{array}{l}\text { Onshore } \\
\text { Contribution } \\
\% \\
\end{array}$} & \multirow[b]{2}{*}{$\begin{array}{l}\text { Offshore } \\
\text { Contribution }\end{array}$} \\
\hline & Onshore & $\begin{array}{r}\text { Offshore } \\
\mu \mathrm{g} / \mathrm{m}^{3}\end{array}$ & All Flares & & \\
\hline Abia & 27 & 4 & 28 & 87 & 13 \\
\hline $\mathrm{AK}$ & 18 & 8 & 23 & 68 & 32 \\
\hline Anambra & 23 & 4 & 24 & 85 & 15 \\
\hline Bayelsa & 8 & 4 & 12 & 67 & 33 \\
\hline Benue & 15 & 4 & 16 & 79 & 21 \\
\hline CR & 17 & 7 & 21 & 71 & 29 \\
\hline Delta & 14 & 4 & 16 & 77 & 23 \\
\hline Ebonyi & 22 & 4 & 23 & 84 & 16 \\
\hline Edo & 12 & 6 & 14 & 67 & 33 \\
\hline Enugu & 21 & 4 & 22 & 83 & 17 \\
\hline Imo & 29 & 5 & 30 & 86 & 14 \\
\hline Kogi & 9 & 3 & 10 & 74 & 26 \\
\hline Ondo & 3 & 2 & 4 & 64 & 36 \\
\hline Rivers & 21 & 4 & 22 & 86 & 14 \\
\hline
\end{tabular}

619

620

621

622

623

624

625

626

627

628

629

630 


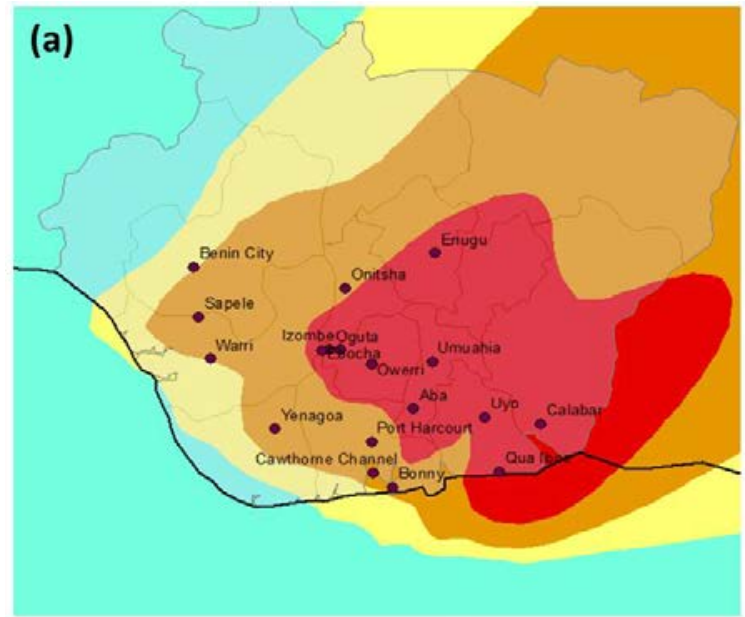

$\mathrm{NO}_{2}$ Pollution Risk Classification $\left(\mu \mathrm{g} / \mathrm{m}^{3}\right)$

$\square$ Very Low (<10) $\square$ Low (10-20) $\square$ Moderate (20-40) $\square$ High (>40)

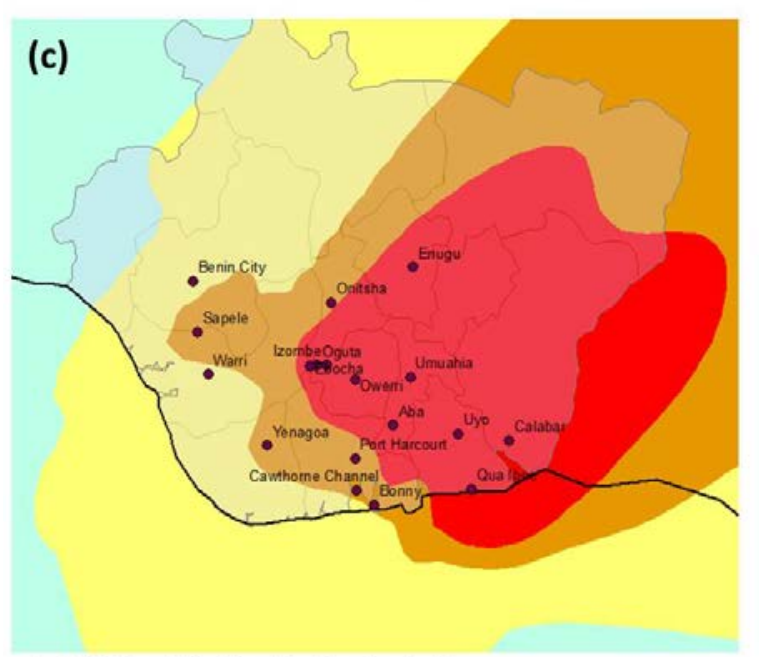

$\mathrm{O}_{3}$ Pollution Risk Classification $\left(\mu \mathrm{g} / \mathrm{m}^{3}\right)$

632

$\square$ Very Low (<20) $\square$ Low (20-60) $\square$ Moderate (60-100)

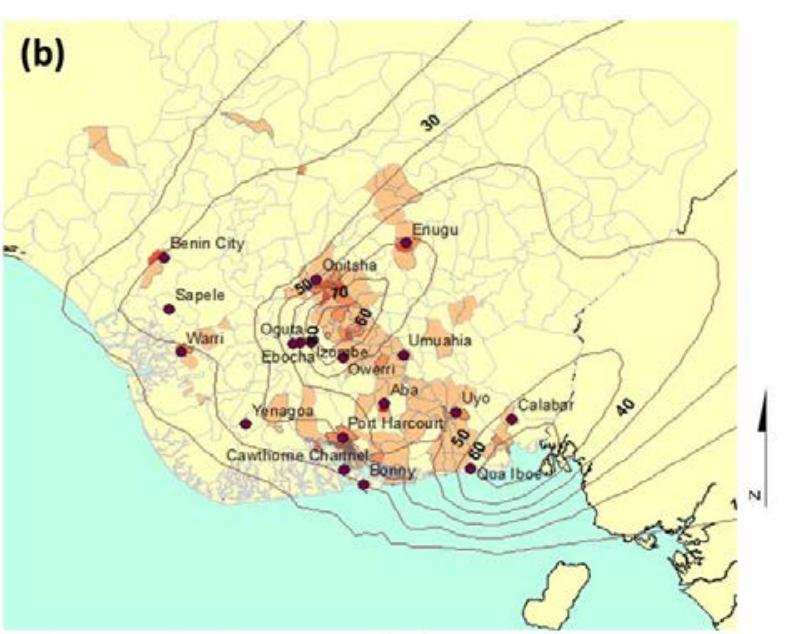

Population Density (population/ $/ \mathrm{Km}^{2}$ )

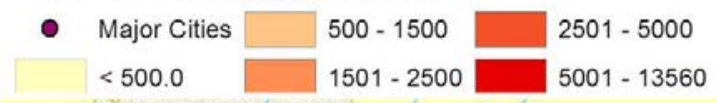

(d)

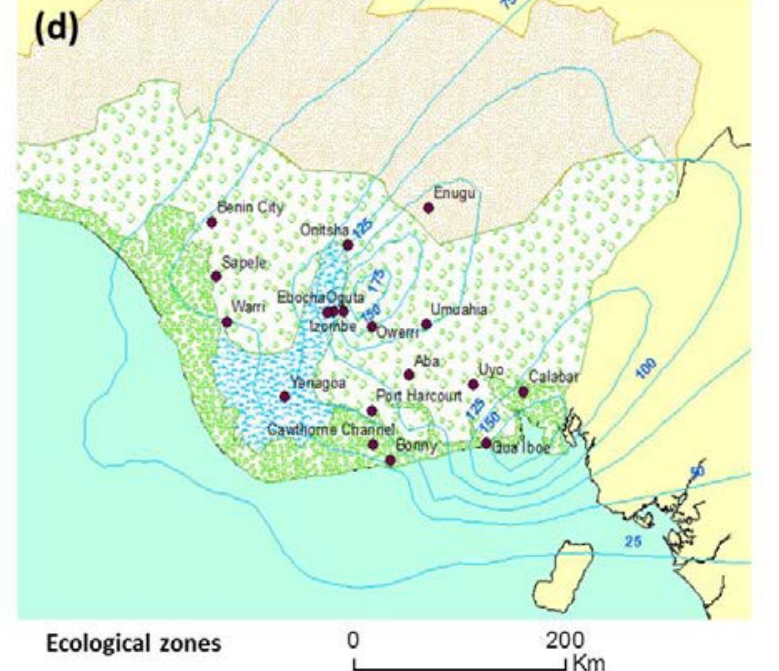

Freshwater Mangrove Rainforest Savannah 
Figure 8

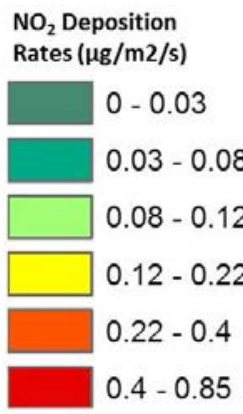

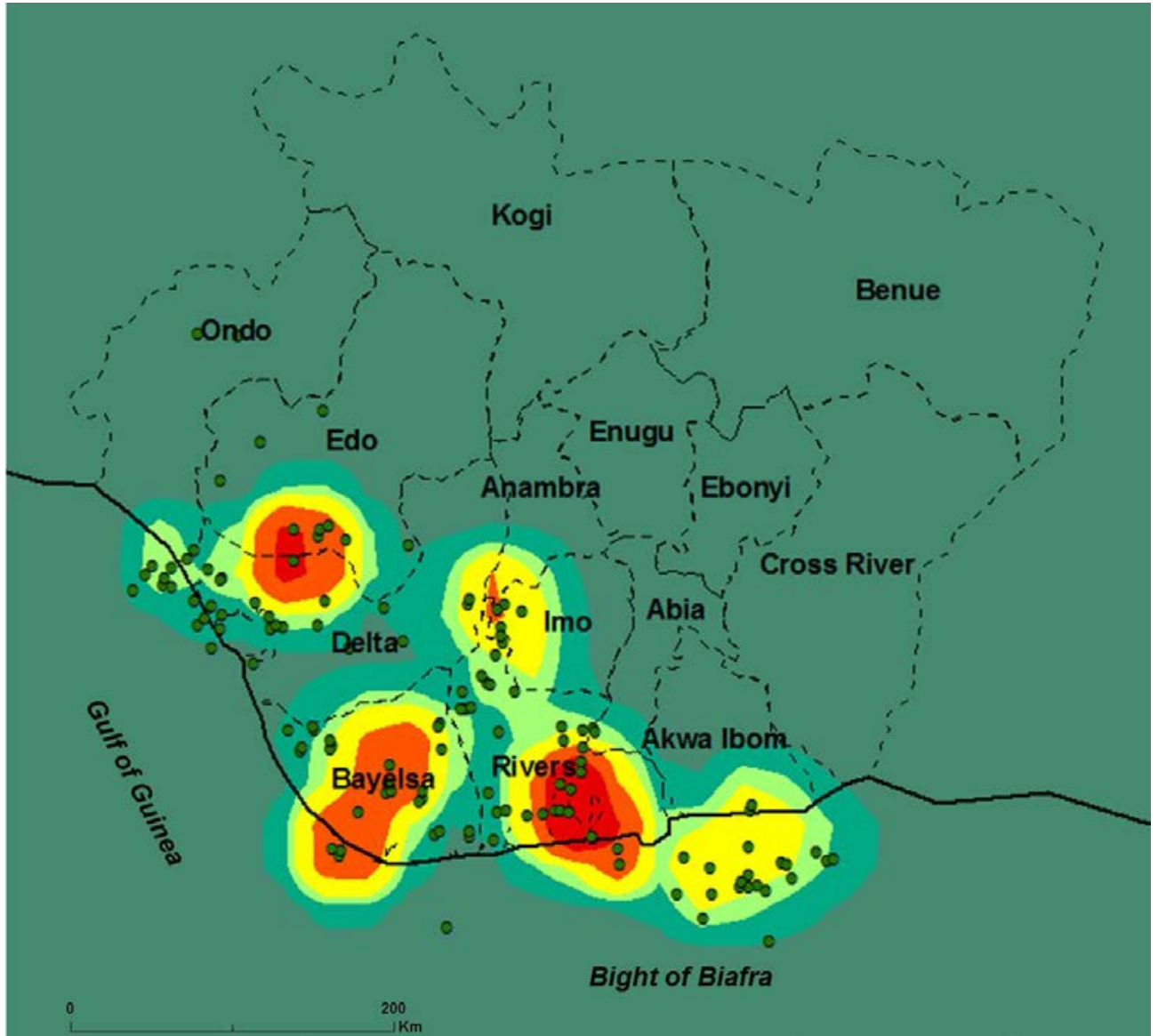

